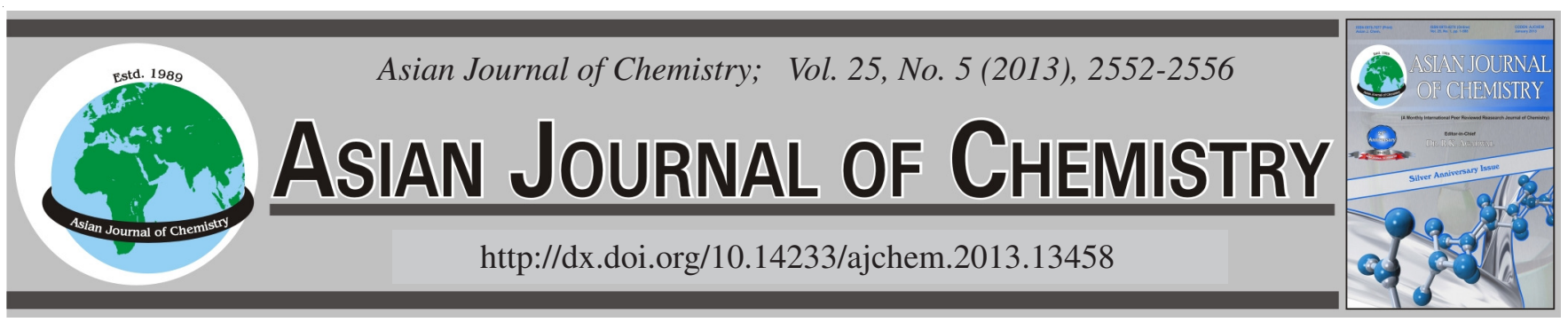

\title{
Synchronous Fluorescence Determination of Streptomycin in Biological Fluids with CdTe/CdSe Quantum Dots as Fluorescence Probe
}

\author{
Yongliang MaO ${ }^{1,2}, \mathrm{Na} \mathrm{Li}^{2}, \mathrm{Ye} \mathrm{Han}^{1}, \mathrm{NAN} \mathrm{LiU}^{3}$, Zhixian GaO ${ }^{3}$ and ZhiJiang Zhou ${ }^{1, *}$
}

${ }^{1}$ School of Chemical Engineering and Technology, Tianjin University, Tianjin, P.R. China

${ }^{2}$ College of Science, Liaoning Technical University, Fuxin, P.R. China

${ }^{3}$ Tianjin Key Laboratory of Risk Assessment and Control Technology for Environment \& Food Safety, Institute of Health and Environmental Medicine, Tianjin, P.R. China

*Corresponding author: E-mail: zzjtju@126.com

\begin{abstract}
A simple, rapid and sensitive synchronous fluorescence method was developed for the determination of streptomycin in biological fluids. When trace amounts of streptomycin was added into the $\mathrm{CdTe} / \mathrm{CdSe}$ core/shell quantum dots solution, the synchronous fluorescence intensity of the system was significantly enhanced. With $\Delta \lambda=230 \mathrm{~nm}$, maximum synchronous fluorescence at $\mathrm{pH} 8.5$ was generated at $345 \mathrm{~nm}$. Under optimum conditions, a good linear relationship between the fluorescence intensity and the streptomycin concentration was obtained in the range from 1.0 to $10 \mu \mathrm{mol} \mathrm{L}^{-1}$ with a correlation coefficient of 0.9971 . The corresponding detection limit was $25 \mathrm{nmol} \mathrm{L}^{-1}$ for streptomycin. Furthermore, some common metal ions, amino acids and some pharmaceuticals, which were regularly used together with streptomycin in medicine, did not interfere with the determination of streptomycin under general conditions. This method was successfully applied to determine streptomycin in human serum and urine samples and the satisfactory results were obtained. In addition, the possible mechanism of the fluorescence enhancement was also discussed.
\end{abstract}

Key Words: Streptomycin, Synchronous fluorescence, CdTe/CdSe, Quantum dots, Biological fluids.

\section{INTRODUCTION}

Streptomycin is an aminoglycoside antibiotic which shows activity against numerous gram-negative bacteria and grampositive bacteria. It has been widely used for the treatment of some infectious diseases in both human and veterinary ${ }^{1,2}$. However, misuse of streptomycin may lead to potential damange in vestibular and auditory functions. Therefore, route pharmaceutical analyses, pharmaceutical dynamic studies and its residual detection require a simple, rapid and sensitive analytical techniques for the determination of its presence in pharmaceutical formulations and biological fluids. Several techniques have thus been employed to analyze streptomycin such as spectrophotometry ${ }^{3}$, high-performance liquid chromatography ${ }^{4}$, gas chromatography-mass spectrometry $(\mathrm{GC}-\mathrm{MS})^{5}$, liquid chromatography-tandem mass spectrometry (LC-MS) ${ }^{6}$, enzyme linked immunofiltration assay $(\text { ELIFA })^{7}$, capillary zone electrophoresis $(\mathrm{CZE})^{8}$ and ion-pair chromatography (IPC) methods ${ }^{9}$. However, these methods involved complicated and time-consuming pretreatment procedures and required expensive or special instruments, which limited their application.
Recently, quantum dots have gained increasing interest during the past decade due to their novel properties and biomedical applications ${ }^{10}$. Compared with traditional organic dye, quantum dots have the following characteristics: broad absorption, narrow emission, size-tunable optical property and photostability ${ }^{11,12}$. However, these conventional fluorescence methods cannot be applied to determine streptomycin in biological fluids because of the interferences with some overlaps of the fluorescence spectra of the existing proteins and other organic substances in biological fluids. Nowadays synchronous fluorescence spectrometry has become an attractive method for detecting drugs and biomolecules ${ }^{13,14}$. Since synchronous fluorescence technology can provide a simplified spectrum and avoid some overlapping spectra and interferences such as Rayleigh-scattering and Raman-scattering, it is robust for quantitative determination in a single measurement.

In this present work, when streptomycin was added into the $\mathrm{CdTe} / \mathrm{CdSe}$ quantum dots solution, the synchronous fluorescence intensity of the system was significantly enhanced. Furthermore, synchronous fluorescence technology was employed to eliminate the interferences from the residual proteins and other organic substances in biological fluids. 
Present method was then used to determine trace amounts of streptomycin in the actual biological fluids and the results were satisfactory. In addition, the possible reaction mechanism was also discussed.

\section{EXPERIMENTAL}

Thioglycolic acid (TGA, $90 \%$ ), $\mathrm{CdCl}_{2} \cdot 2.5 \mathrm{H}_{2} \mathrm{O}, \mathrm{Te}$ powder, $\mathrm{NaBH}_{4}$ and other routine chemicals was purchased from Tianjin Guangfu Fine Chemical Research Institute (Tianjin, China) and used as received without further purification. All amino acids were acquired from Beijing Biotechnology Co. (Beijing, China). Streptomycin (99.9 \%) was obtained from Sigma Chemical Co. (St. Louis, USA). All chemicals were of analytical grade or better. Double deionized water was used throughout the whole work.

The fluorescence spectra and intensities were obtained by a F-4500 fluorescence spectrophotometer (Hitachi, Tokyo, Japan) equipped with a plotter unit and a quartz cell $(1 \mathrm{~cm} \times 1$ $\mathrm{cm})$. All absorption spectra were recorded with a U-3010 Spectrophotometer (Hitachi, Tokyo, Japan). Transmission electron microscopy (TEM) images of quantum dots were performed on a JEOL-2010 transmission electron microscope (Jeol, Tokyo, Japan) using an acceleration voltage of $200 \mathrm{kV}$. All pH measurements were made with a PHS-3C digital $\mathrm{pH}$ meter (Leici, Shanghai, China). A Sigma 3-30K refrigerated centrifuge (Sigma, Göttingen, Germany) was used to centrifugate samples of human serum and urine.

Synthesis of CdTe/CdSe quantum dots: $\mathrm{CdTe} / \mathrm{CdSe}$ core/shell quantum dots were prepared in aqueous solution according to previous method with some modification ${ }^{15,16}$. Briefly, freshly made NaHTe solution was injected into a mixture solution ( $\mathrm{pH}$ 9.5) of $\mathrm{CdCl}_{2}$ and thioglycolic acid after 20 min of degassing with argon. The molar ratio of $\mathrm{Cd}^{2+}:$ TGA:Te was $1: 2: 0.25$. The crude solution was refluxed at $100{ }^{\circ} \mathrm{C}$ for $3 \mathrm{~h}$ to promote the growth of CdTe quantum dots. Then, a degassed mixture solution ( $\mathrm{pH}$ 9.5) of $\mathrm{CdCl}_{2}$, thioglycolic acid and $\mathrm{Na}_{2} \mathrm{SeSO}_{3}$ were injected into the reaction system of the CdTe quantum dots solution sequentially by dropwise addition with syringes and then refluxed for $30 \mathrm{~min}$. Thus, the first layer of CdSe shell was formed. Repeating the above procedure four times, $\mathrm{CdTe} / \mathrm{CdSe}$ quantum dots was finally synthesized.

Sample treatment: The human serum and urine samples were collected from healthy volunteers. Streptomycin residue and its metabolic product were extracted as follows: $1 \mathrm{~mL}$ human serum and urine samples was transferred to a $10 \mathrm{~mL}$ centrifuge tube, then $2 \mathrm{~mL}$ acetonitrile was added. The mixture was shaken for $10 \mathrm{~min}$ and then centrifugated at $6000 \mathrm{rpm}$ for $10 \mathrm{~min}$ to precipitate proteins. The supernates were directly collected and diluted to volume with double deionized water just before the determination. The recovery tests in the human serum and urine samples were performed as follows: the samples were spiked with routine amounts of streptomycin stock solution, the extraction process was employed as the above procedures.

Procedure for synchronous fluorescence determination of streptomycin: In a $10 \mathrm{~mL}$ calibrated test tube, $1 \mathrm{~mL}$ of the $\mathrm{CdTe} / \mathrm{CdSe} \mathrm{QD}$ solution, $1 \mathrm{~mL}$ of Tris- $\mathrm{HCl}$ buffer solution
(pH 8.5) and $0.8 \mathrm{~mL}$ of streptomycin solution with standard concentration or extracts from samples were sequentially added. The mixture was diluted to volume with double deionized water, shaken and allowed to stand for $10 \mathrm{~min}$. The synchronous fluorescence intensity of the system was measured at $345 \mathrm{~nm}$ with $\Delta \lambda=230 \mathrm{~nm}$. The excitation and emission slit widths for all fluorescence measurements were maintained at $5 \mathrm{~nm}$.

\section{RESULTS AND DISCUSSION}

Characterization of $\mathrm{CdTe} / \mathrm{CdSe}$ core/shell quantum dots: Fig. 1. showed the UV-visible adsorption and fluorescence spectra of the original $\mathrm{CdTe}$ core and corresponding $\mathrm{CdTe} /$ $\mathrm{CdSe}$ quantum dots. The maximum absorbance of the CdTe core was $480 \mathrm{~nm}$. When the CdTe core was coated with CdSe shell, the maximum absorption was found to be red-shift to $550 \mathrm{~nm}$. In addition, the emission wavelength of the original CdTe core was narrow and symmetrical with a sharp emission peak at $535 \mathrm{~nm}$. With the growth of the shell thickness, a significant red shift of the maximum emission wavelength from $535 \mathrm{~nm}$ to $590 \mathrm{~nm}$ was observed. Furthermore, any increase observed in the sizes of the quantum dots could be also ascribed to the shell growth. As shown in Fig. 2, the structure of the $\mathrm{CdTe} / \mathrm{CdSe}$ quantum dots consisted of CdTe (core) with a radius of $1.6 \mathrm{~nm}, \mathrm{CdSe}$ (shell) with a thickness of $1.8 \mathrm{~nm}$.

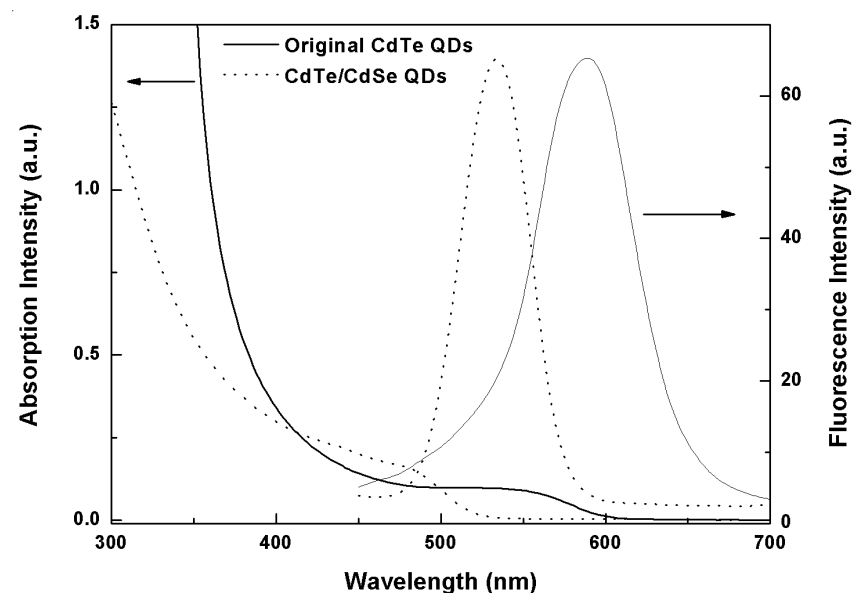

Fig. 1. UV-visible absorption and fluorescence spectra of the original CdTe quantum dots and corresponding $\mathrm{CdTe} / \mathrm{CdTe}$ core/shell quantum dots
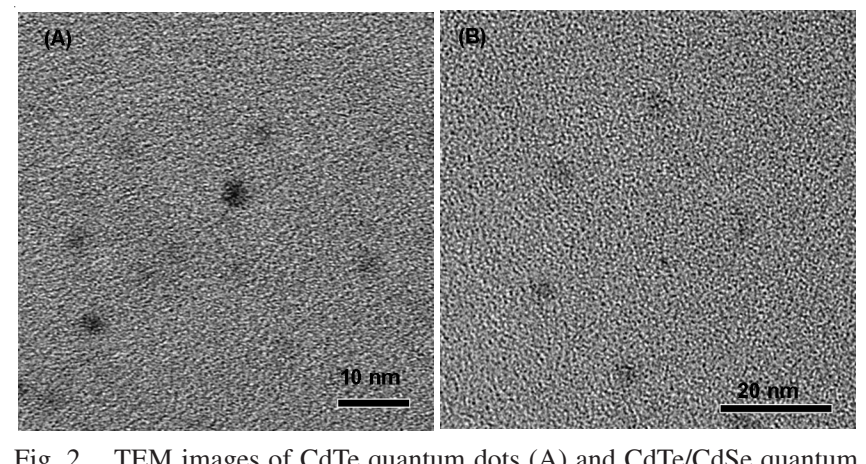

Fig. 2. TEM images of CdTe quantum dots (A) and CdTe/CdSe quantum dots (B). The scale bars are 10 and $20 \mathrm{~nm}$, respectively

Fluorescence spectral characteristics of $\mathrm{CdTe} / \mathrm{CdSe}$ quantum dots: The fluorescence intensity of $\mathrm{CdTe} / \mathrm{CdSe}$ 
TABLE-1

TESTS FOR THE INTERFERENCE OF COEXISTING SUBSTANCES ${ }^{a}$

\begin{tabular}{lccccc}
\hline $\begin{array}{l}\text { Coexisting } \\
\text { substance }\end{array}$ & $\begin{array}{c}\text { Coexisting concentration } \\
(\mu \mathrm{mol} \mathrm{L})\end{array}$ & $\begin{array}{c}\text { Change of synchronous } \\
\text { fluorescence intensity }(\%)\end{array}$ & $\begin{array}{c}\text { Coexisting } \\
\text { substance }\end{array}$ & $\begin{array}{c}\text { Coexisting } \\
\text { concentration }\left(\mu \mathrm{mol} \mathrm{L}^{-1}\right)\end{array}$ & $\begin{array}{c}\text { Change of Synchronous } \\
\text { fluorescence intensity }(\%)\end{array}$ \\
\hline L-Phenylalanine & 5 & -4.1 & $\mathrm{~K}^{+}$ & 500 & -3.7 \\
L-Leucine & 5 & -3.3 & $\mathrm{Na}^{+}$ & 5000 & -3.3 \\
Isoleucine & 10 & -2.2 & $\mathrm{Mg}^{2+}$ & 100 & -4.8 \\
L-Cysteine & 5 & -3.8 & $\mathrm{Mn}^{2+}$ & 100 & -2.6 \\
L-Proline & 5 & -2.7 & $\mathrm{Ca}^{2+}$ & 50 & -5.4 \\
Arginine & 10 & -4.0 & $\mathrm{Zn}^{2+}$ & 50 & -4.4 \\
Lysine & 10 & -3.7 & $\mathrm{Al}^{3+}$ & 50 & 4.0 \\
Glucose & 10 & -3.1 & $\mathrm{Ba}^{2+}$ & 20 & -2.9 \\
Citric acid & 10 & -2.0 & $\mathrm{Hg}^{2+}$ & 0.2 & -2.7 \\
Kanamycin & 10 & 3.1 & $\mathrm{~Pb}^{2+}$ & 0.2 & -4.7 \\
Gentamycin & 10 & 2.7 & $\mathrm{Ag}^{+}$ & 0.2 & -3.2 \\
Neomycin & 5 & 4.9 & $\mathrm{Cu}^{2+}$ & 0.2 & -3.6 \\
\hline${ }^{a}$ CdTe/CdSe QDs: $25 \mu \mathrm{mol} \mathrm{L} \mathrm{L}^{-1}, \mathrm{STR}: 10.0 \mu \mathrm{mol} \mathrm{L}{ }^{-1}, \mathrm{pH}=8.5$ & & &
\end{tabular}

quantum dots was significantly enhanced in the presence of streptomycin, which indicated a new fluorescent method would be established to determine streptomycin. However, the application of this method was limited except in the pharmaceutical formulation and it could not be used to determine streptomycin in biological fluids. Although some proteins was removed in the sample preparation process, protein residues and other organic substances existed in biological fluids would seriously interfere with the determination of streptomycin, because their fluorescence peaks had some overlaps. In order to extend its application to determine streptomycin in biological fluids, the synchronous fluorescence technology was employed. To eliminate the interferences caused by the protein residues and other organic substances in biological fluids, the optimum $\Delta \lambda$ value was selected based on the interferences in biological fluids and the fluorescence intensity of the system. The results indicated when $\Delta \lambda=230 \mathrm{~nm}$, the synchronous fluorescence peak of $\mathrm{CdTe} / \mathrm{CdSe}$ quantum dots was at $345 \mathrm{~nm}$ and the fluorescence peak of proteins could be separated from that of $\mathrm{CdTe} /$ CdSe quantum dots. Thus, $\Delta \lambda=230 \mathrm{~nm}$ were selected for further study.

Optimization of the influencing factors on the relative synchronous fluorescence intensity of the system: It has been reported that the $\mathrm{pH}$ values has a great influence on the fluorescence intensity of quantum dots ${ }^{17,18}$. Here, the effect of $\mathrm{pH}$ value on the synchronous fluorescence intensity of $\mathrm{CdTe} /$ $\mathrm{CdSe}$ quantum dots was investigated from 5 to 9 . As seen in Fig. 3, the synchronous fluorescence intensity of the system kept increasing as the $\mathrm{pH}$ values ranged from 5.0 to 8.5 and then decreased when the $\mathrm{pH}$ values increased to 9.0. According to that, a $\mathrm{pH}$ of 8.5 was recommended for subsequence experiments.

The optimal concentration of quantum dots should give the highest sensitivity and the widest linear range of the calibration graphs ${ }^{19}$. When the concentration of $\mathrm{CdTe} / \mathrm{CdSe}$ quantum dots was low, the significant fluorescence enhancement of the system could be obtained and the sensitivity was relatively high. With increasing the concentration of $\mathrm{CdTe} / \mathrm{CdSe}$ quantum dots, the linear range of calibration graphs became wider whereas the sensitivity decreased. Take into account of both the sensitivity and the linear range, $25 \mu \mathrm{mol} \mathrm{L} \mathrm{L}^{-1}$ of $\mathrm{CdTe} / \mathrm{CdSe}$ solution was employed for further research.

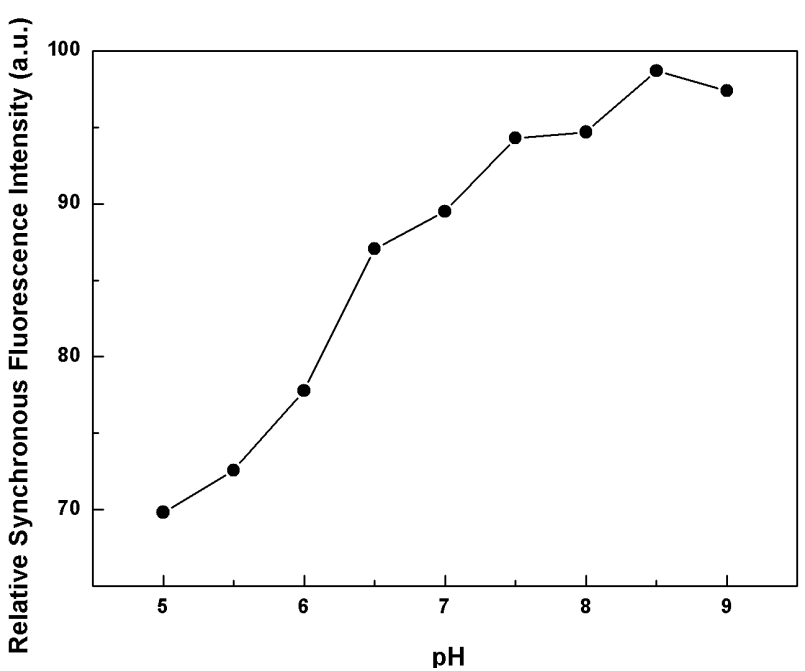

Fig. 3. Effect of $\mathrm{pH}$ on the synchronous fluorescence intensity of the system. Condition: $\mathrm{CdTe} / \mathrm{CdSe}$ quantum dots: $25 \mu \mathrm{mol} \mathrm{L} \mathrm{L}^{-1}$, streptomycin: $5.0 \mu \mathrm{mol} \mathrm{L}-1$

It displayed in Fig. 4, the reaction between $\mathrm{CdTe} / \mathrm{CdSe}$ quantum dots and streptomycin reached the equilibrium within $10 \mathrm{~min}$ and the synchronous fluorescence signals remained stable at least for $20 \mathrm{~min}$ at room temperature $\left(25 \pm 2{ }^{\circ} \mathrm{C}\right)$. Hereby, all the measurements were performed after $10 \mathrm{~min}$ incubation.

Interference of coexisting foreign substances: Under the optimal conditions, some common metal ions, amino acids and some pharmaceuticals were possibly used together with streptomycin in medicine were examined for interferences. The results was listed in Table- 1 . Table- 1 showed that when the concentrations of the foreign substances were close to the concentration of streptomycin, most of them did not interfere with the determination. Whereas, some heavy metal ions, such as $\mathrm{Hg}^{2+}, \mathrm{Pb}^{2+}, \mathrm{Ag}^{+}$and $\mathrm{Cu}^{2+}$ would interfere with the determination of streptomycin. However, the possible interference from these metal ions could be eliminated effectively by filtering the sample solutions using mercapto-cotton ${ }^{20}$. In addition, three types of aminoglycoside antibiotics were also examined for interferences. The results showed that neomycin would interfere with the determination and which did not influence its application on the determination of streptomycin in biological fluids. Because they belonged to the same types 
of aminoglycoside antibiotics, they could not be used simultaneously for the treatment of some infectious diseases.

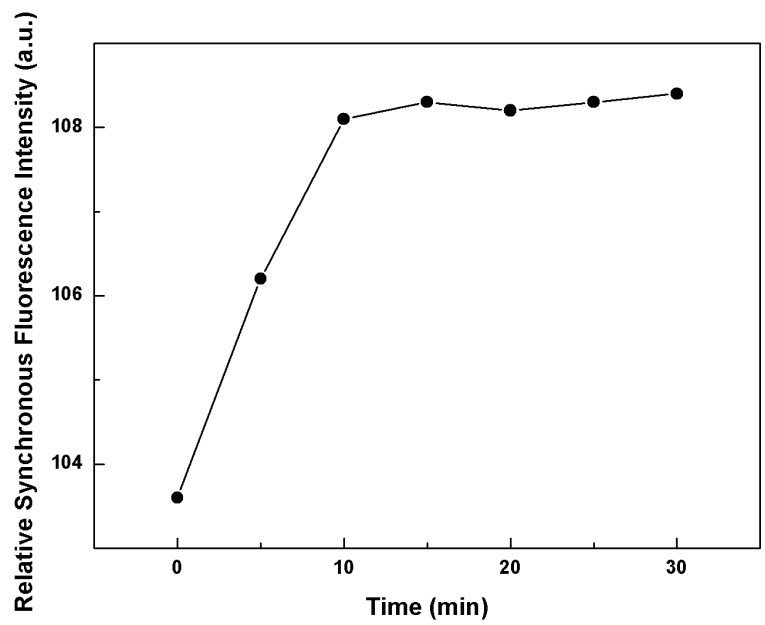

Fig. 4. Effect of reaction time on the synchronous fluorescence intensity of the system. Condition: CdTe/CdSe quantum dots: $25 \mu \mathrm{mol} \mathrm{L}{ }^{-1}$, streptomycin: $5.0 \mu \mathrm{mol} \mathrm{L}{ }^{-1}, \mathrm{pH}=8.5$

Calibration graphs and sensitivity: The synchronous fluorescence spectra were obtained by scanning simultaneously the excitation and emission monochromators. Thus, the relationship of the synchronous fluorescence intensity should be directly proportional to the concentration of streptomycin. Under the optimal conditions, the calibration graphs for the determination of streptomycin were shown in Fig. 5. The proportional correlation of the enhancement intensity of synchronous fluorescence with the concentration of streptomycin was in the range of 0.1 to $1.0 \mu \mathrm{mol} \mathrm{\textrm {L } ^ { - 1 }}$ with a correlation coefficient of 0.9971 , the linear regression equation was $\mathrm{I}_{\mathrm{SF}}-$ $\mathrm{I}_{\mathrm{SF} 0}=0.833+2.917 \mathrm{C}\left(\mu \mathrm{mol} \mathrm{L} \mathrm{L}^{-1}\right)$ and the limit of detection (LOD, $\mathrm{S} / \mathrm{N}=3$ ) was $25 \mathrm{nmol} \mathrm{L} \mathrm{L}^{-1}$. The recovery tests showed that the recoveries of streptomycin in human serum and urine samples were in the range 95.0-104.2\% with a relative standard deviation of less than $2.1 \%$, which indicated this method had good precision and accuracy.

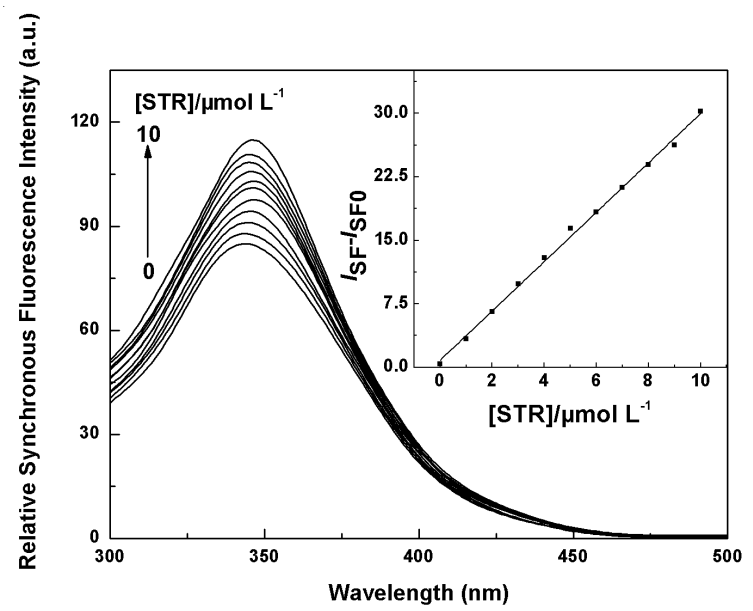

Fig. 5. Synchronous fluorescence intensity of $\mathrm{CdTe} / \mathrm{CdSe}$ quantum dots upon the addition of STR $(1.0,2.0,3.0,4.0,5.0,6.0,7.0,8.0,9.0$ and $\left.10.0 \mu \mathrm{mol} \mathrm{L}{ }^{-1}\right)$. Inset: Plot of synchronous fluorescence enhancement $\left[\mathrm{I}_{\mathrm{SF}}-\mathrm{I}_{\mathrm{SF} 0}\right]$ of CdTe/CdSe quantum dots at emission peak versus [streptomycin]. Condition: $\mathrm{CdTe} / \mathrm{CdSe}$ quantum dots : 25 $\mu \mathrm{mol} \mathrm{L}{ }^{-1}, \mathrm{pH}=8.5$
Determination of streptomycin in human serum and urine samples: The four fresh human serum and urine samples from different volunteers were determined by the proposed method and the HPLC method, respectively. The results were presented in Table-2. Table-2 showed that the concentration of the samples determined by the presented method was in accordance with that of HPLC method. Therefore, the proposed method had great potential for the sensitive and rapid determination of streptomycin in human serum and urine samples.

TABLE-2

ANALYTICAL RESULTS FOR THE DETERMINATION OF

STREPTOMYCIN IN HUMAN SERUM AND URINE SAMPLES BY THE PROPOSED METHOD AND THE HPLC METHOD

\begin{tabular}{lcc|cc}
\hline \multirow{3}{*}{ Sample } & \multicolumn{2}{c|}{ This method } & \multicolumn{2}{c}{ HPLC } \\
\cline { 2 - 5 } & $\begin{array}{c}\text { Found }^{\mathrm{a}} \\
\left.(\mu \mathrm{mol} \mathrm{L})^{-1}\right)\end{array}$ & $\begin{array}{c}\text { R.S.D. } \\
(\%)\end{array}$ & $\begin{array}{c}\text { Found }^{\mathrm{a}} \\
\left(\mu \mathrm{mol} \mathrm{L}^{-1}\right)\end{array}$ & $\begin{array}{c}\text { R.S.D. } \\
(\%)\end{array}$ \\
\hline Human serum 1 & $2.42 \pm 0.056$ & 2.3 & $2.32 \pm 0.0278$ & 1.2 \\
Human serum 2 & $4.68 \pm 0.094$ & 2.0 & $4.51 \pm 0.0722$ & 1.6 \\
Human urine 1 & $3.46 \pm 0.116$ & 3.2 & $3.24 \pm 0.0551$ & 1.7 \\
Human urine 2 & $6.64 \pm 0.173$ & 2.6 & $6.32 \pm 0.0885$ & 1.4 \\
\hline${ }^{a}$ Mean of six replicates $(\mathrm{n}=6)$ & & &
\end{tabular}

Mechanism of reaction: Fig. 5 showed that when streptomycin were added to the quantum dots solution, the fluorescence intensity of the system was significantly enhanced, which indicated that a coordination compound between streptomycin and $\mathrm{CdTe} / \mathrm{CdSe}$ quantum dots was possibly formed. Since the surface of thioglycolic acid-capped CdTe/CdSe particles contain carboxyl group which appear as negative charge, while the amino group of streptomycin display positive charge. It is easy for streptomycin molecules to bind to the surface of CdTe/ CdSe quantum dots through electrostatic attraction. Moreover, with increasing the streptomycin bound on the surface of quantum dots, the compound gradually show positive charge properties and is prone to binding to another negative charged quantum dots via amino group of streptomycin, which would finally induce quantum dots aggregation ${ }^{21}$. Therefore, it was reasonable to assume that the fluorescence enhancement of the system was due to the formation of quantum dots aggregation.

\section{Conclusion}

Based on the fluorescence enhancement of the system, we applied a simple, rapid and sensitive synchronous fluorescence method for the determination of streptomycin in biological fluids. The possible mechanism of reaction was also discussed. Moreover, some common metal ions, amino acids and some pharmaceuticals, which were regularly used together with streptomycin, did not interfere with the determination of streptomycin under general conditions. The proposed method could be applied to directly determine trace amounts of streptomycin in human serum and urine samples with deproteinization treatments. It was possible to become a useful tool for determining streptomycin in the actual human serum and urine.

\section{ACKNOWLEDGEMENTS}

The authors gratefully acknowledge the financial supports by the Nation Nature Science Foundation of China (30800915), the National Science and Technology Supporting Program of 
China (2009BADB9B03-Z05), the National High Technology Research and Development Program of China (2010AA06Z302) and the Science and Technology Program of Tianjin (09ZCKFSH02700).

\section{REFERENCES}

1. M. van. Bruijnsvoort, S.J.M. Ottink, K.M. Jonker and E. de Boer, $J$ Chromatogr. A, 1058, 137 (2004).

2. R.H.M.M. Granjaa, A.M.M. Niño, R.A.M. Zucchetti, R.E.M. Niño, R Patel and A.G. Salerno, Anal. Chim. Acta, 637, 64 (2009).

3. F. Belal, S.M. El-Ashry, M.M. El-Kerdawy and D.R. El-Wasseef, $J$ Pharm. Biomed. Anal., 26, 435 (2001).

4. O. Granados and G. Meza, J. Pharm. Biomed. Anal., 43, 625 (2007).

5. M. Preu and M. Petz, J. Chromatogr. A, 840, 81 (1999).

6. M. Pendela, J. Hoogmartens, A.V. Schepdael and E. Adams, J. Sep. Sci., 32, 3418 (2009).

7. P. Schnaoppinger, E. Schneider, E. Maertlbauer and G. Terplan, Food Agric. Immunol., 8, 269 (1996).

8. P.P. Maia, J.A. Farfán, S. Rath and F.G.R. Reyes, J. Pharm. Biomed. Anal., 43, 450 (2007).
9. A.M. Gremilogianni, N.C. Megoulas and M.A. Koupparis, J. Chromatogr. A, 1217, 6646 (2010).

10. A.P. Alivisatos, Science, 271, 933 (1996).

11. W.C.W. Chan and S.M. Nie, Science, 281, 2016 (1998).

12. I.L. Medintz, H.T. Uyeda, E.R. Goldman and H. Mattoussi, Nat. Mater., 4, 435 (2005)

13. Z. Hu and C.L. Tong, Anal. Chim. Acta, 587, 187 (2007).

14. L.Y. Wang, Y.Y. Zhou, L. Wang, C.Q. Zhu, Y.X. Li and F. Gao, Anal. Chim. Acta, 466, 87 (2002).

15. Y.S. Xia and C.Q. Zhu, Analyst, 133, 928 (2008).

16. Y. Zhang, Y. Li and X.P. Yan, Small, 5, 185 (2009).

17. Y.Q. Wang, C. Ye, Z.H. Zhu and Y.Z. Hu, Anal. Chim. Acta, 610, 50 (2008).

18. H. Zhang, Z. Zhou and B. Yang, J. Phys. Chem. B, 107, 8 (2003).

19. A.N. Liang, L. Wang, H.Q. Chen, B.B. Qian, B. Ling and J. Fu, Talanta, 81, 438 (2010).

20. X.L. Diao, Y.S. Xia, T.L. Zhang, Y. Li and C.Q. Zhu, Anal. Bioanal. Chem., 388, 1191 (2007).

21. L. Wang, J.J. Peng, Z.W. Liu and Y.Q. He, Luminescence, 25, 424 (2010). 